\title{
Spacecraft Life Support Systems
}

\&

John A. Hogan, Ph.D. Bioengineering Branch NASA Ames Research Center 


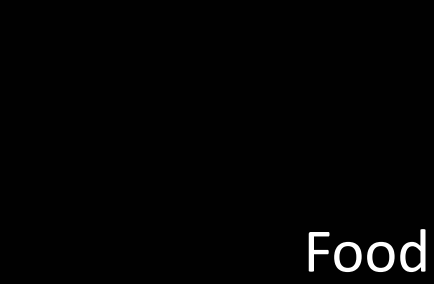

Water
Pressure

Air

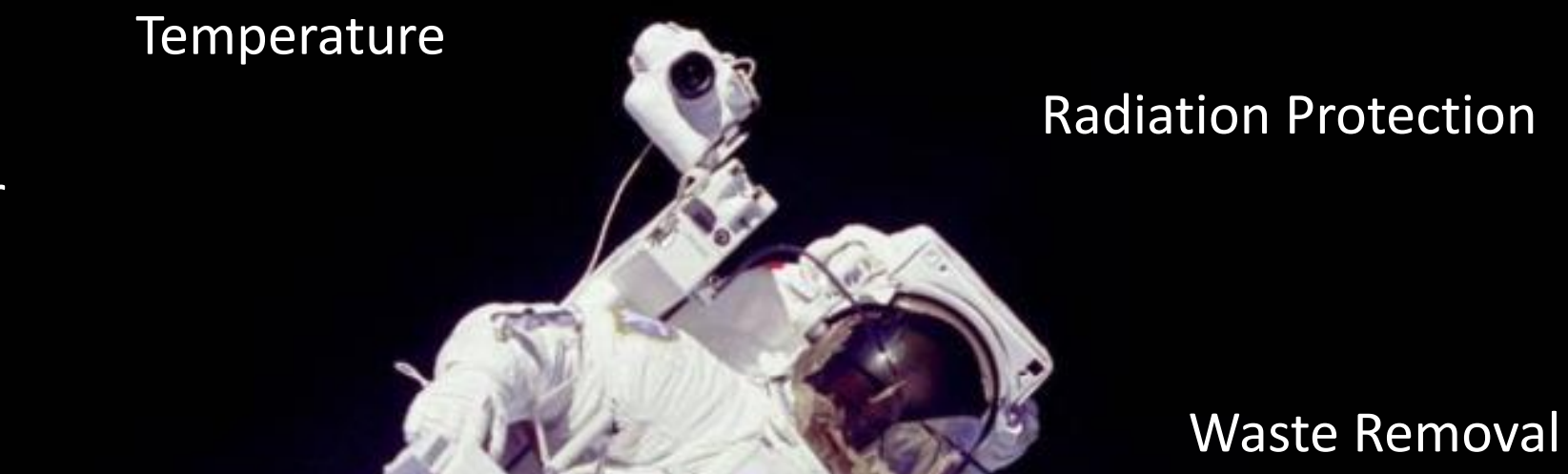


NASA Earth's Life Support Systems (ELSS) 


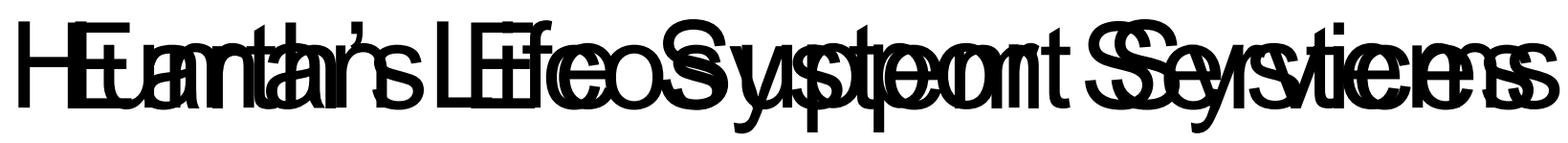

Water/waste purification
Air quality regulation
Aesthetic/Spiritual values Recreation/Ecotourism

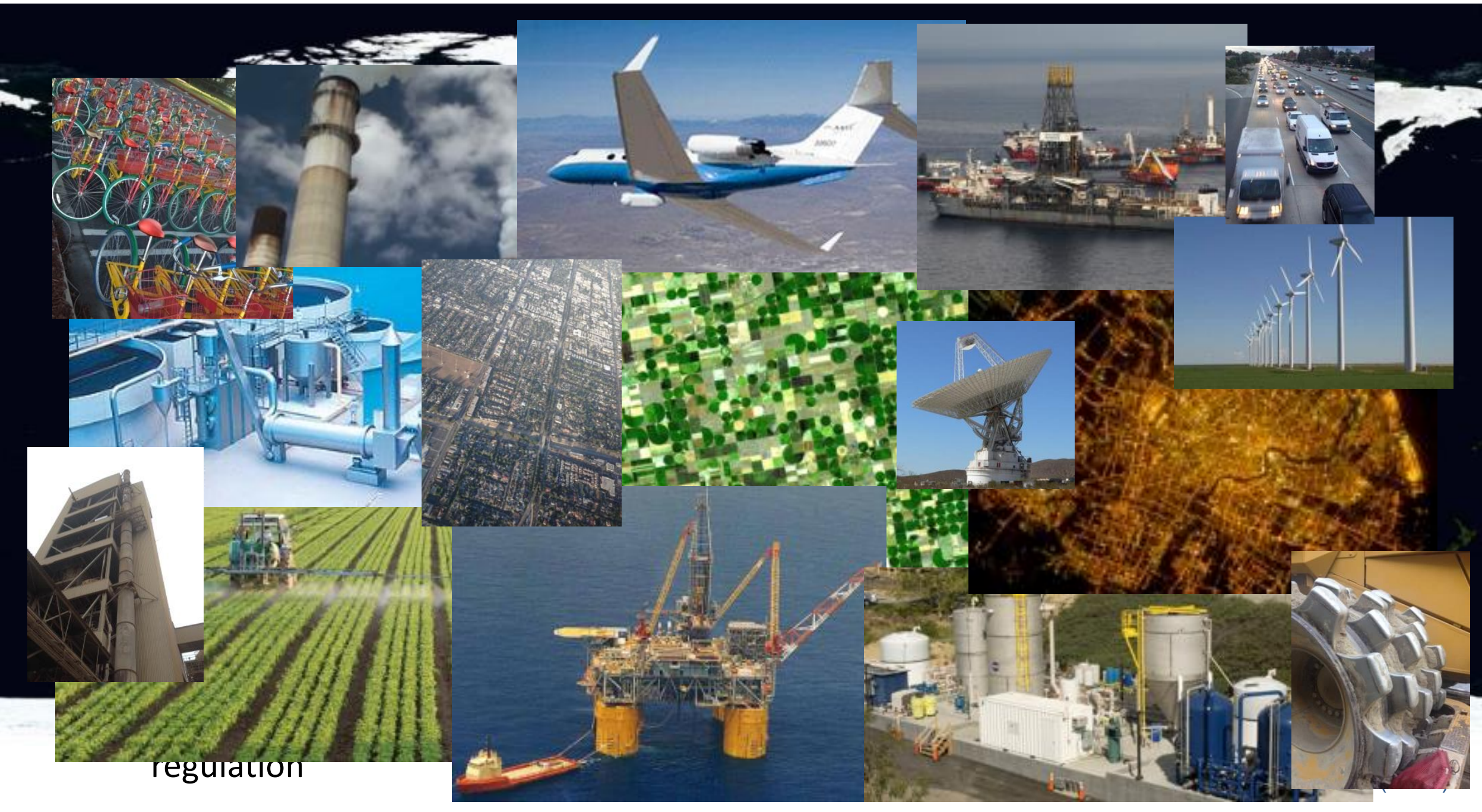




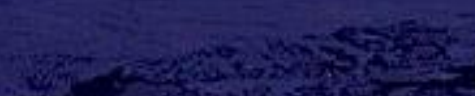

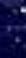

$+2$

$\because$

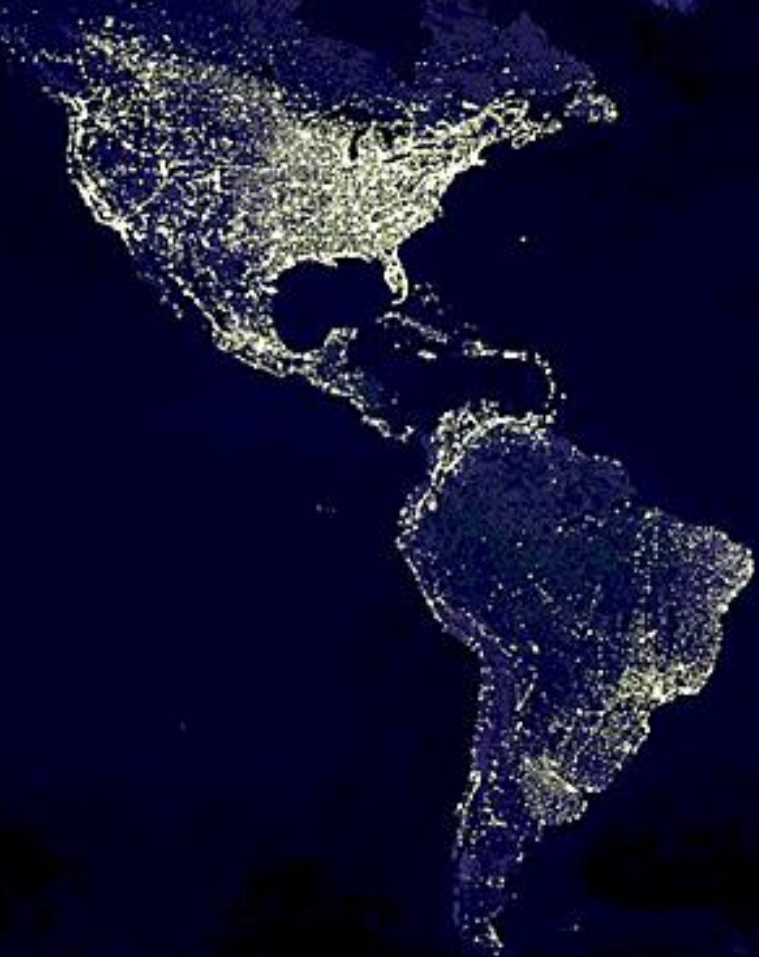

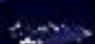

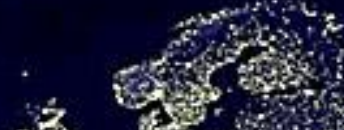

1.9.

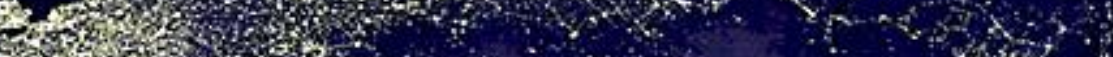

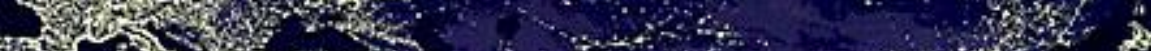

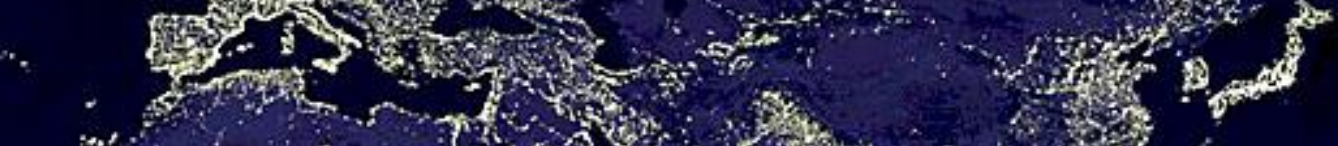

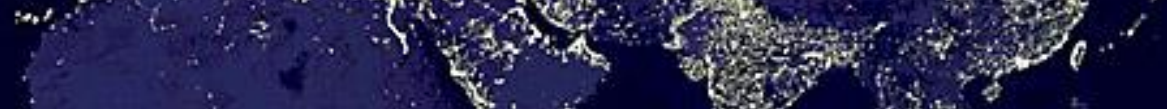

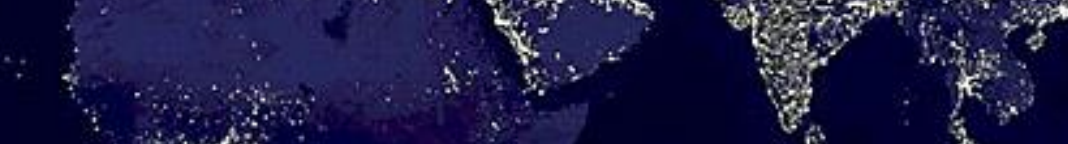

W.

:

is:

(3.

$+3$
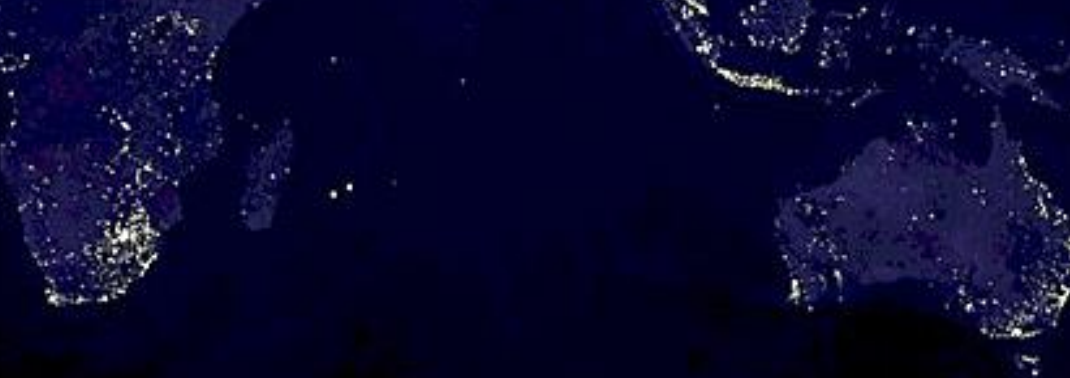


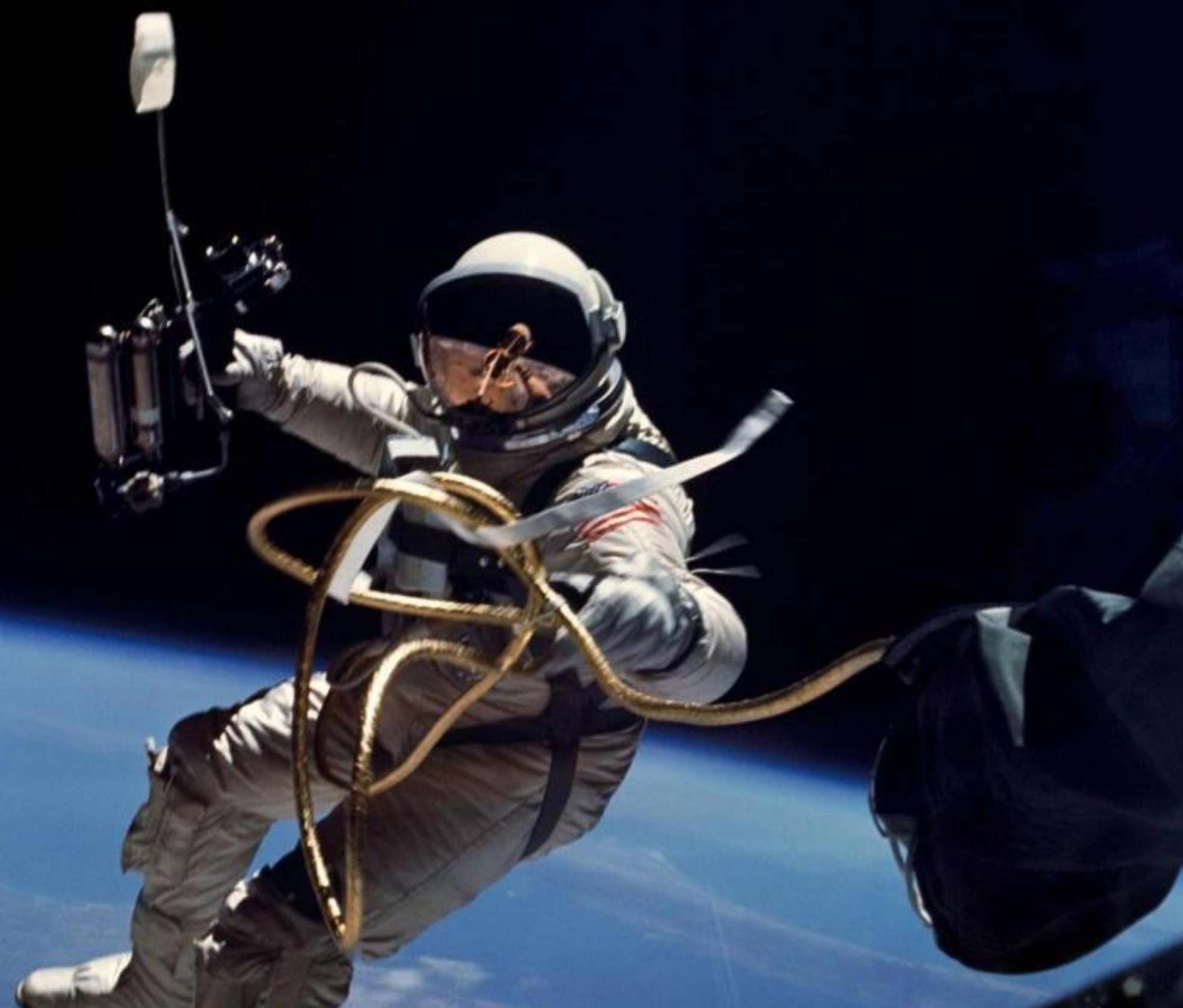




\section{Early Missions}
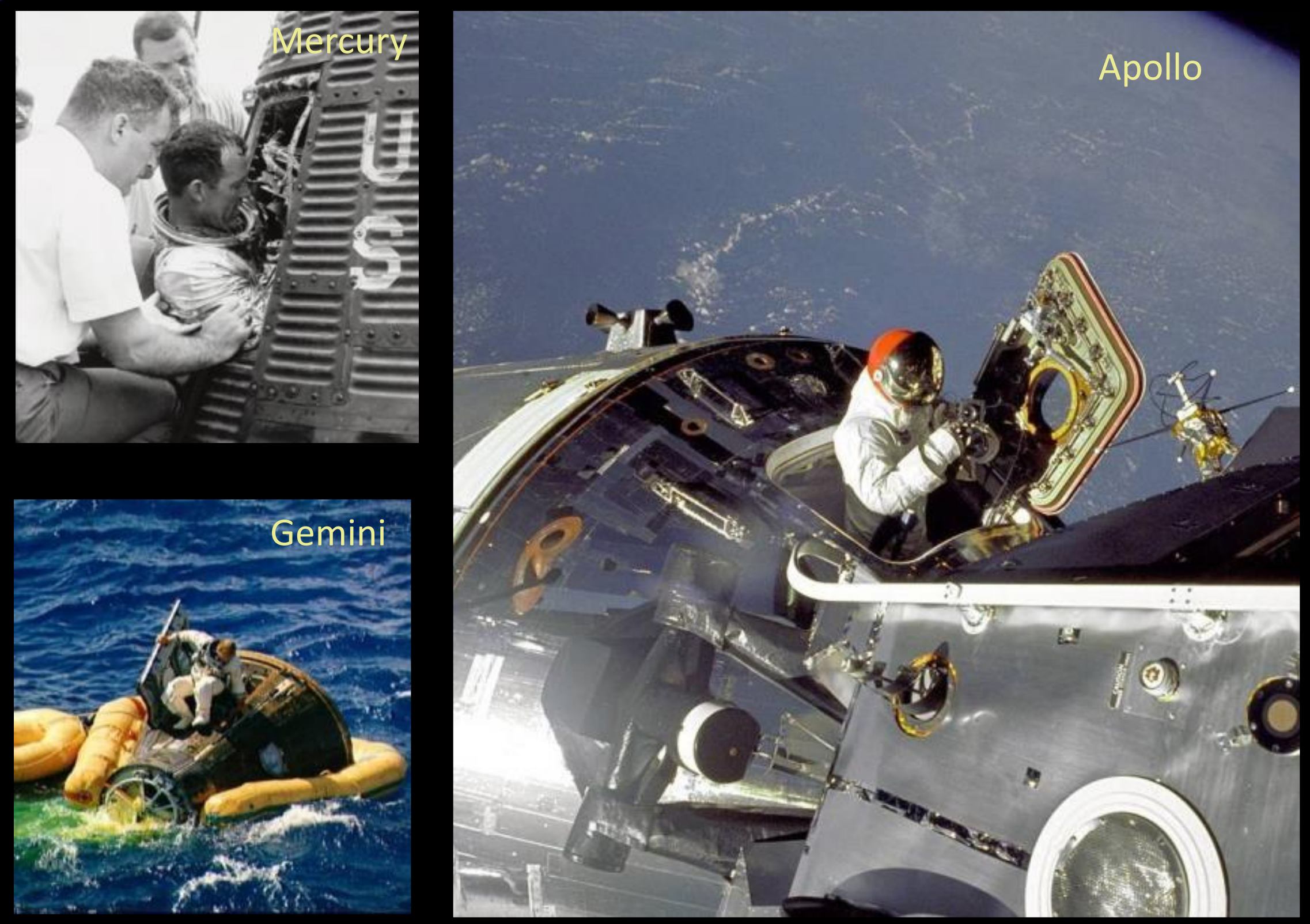


\section{NAGA \\ SKYLAB}

3 Missions - 28, 59, 84 days

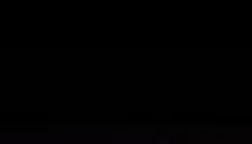


NASA

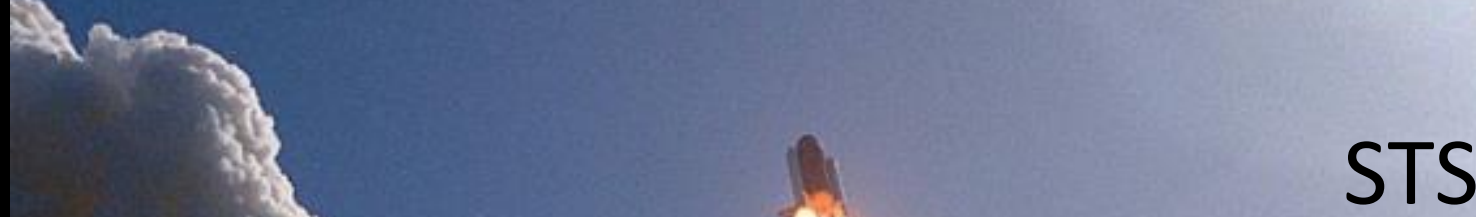




\section{NASA}

\section{International Space Station}

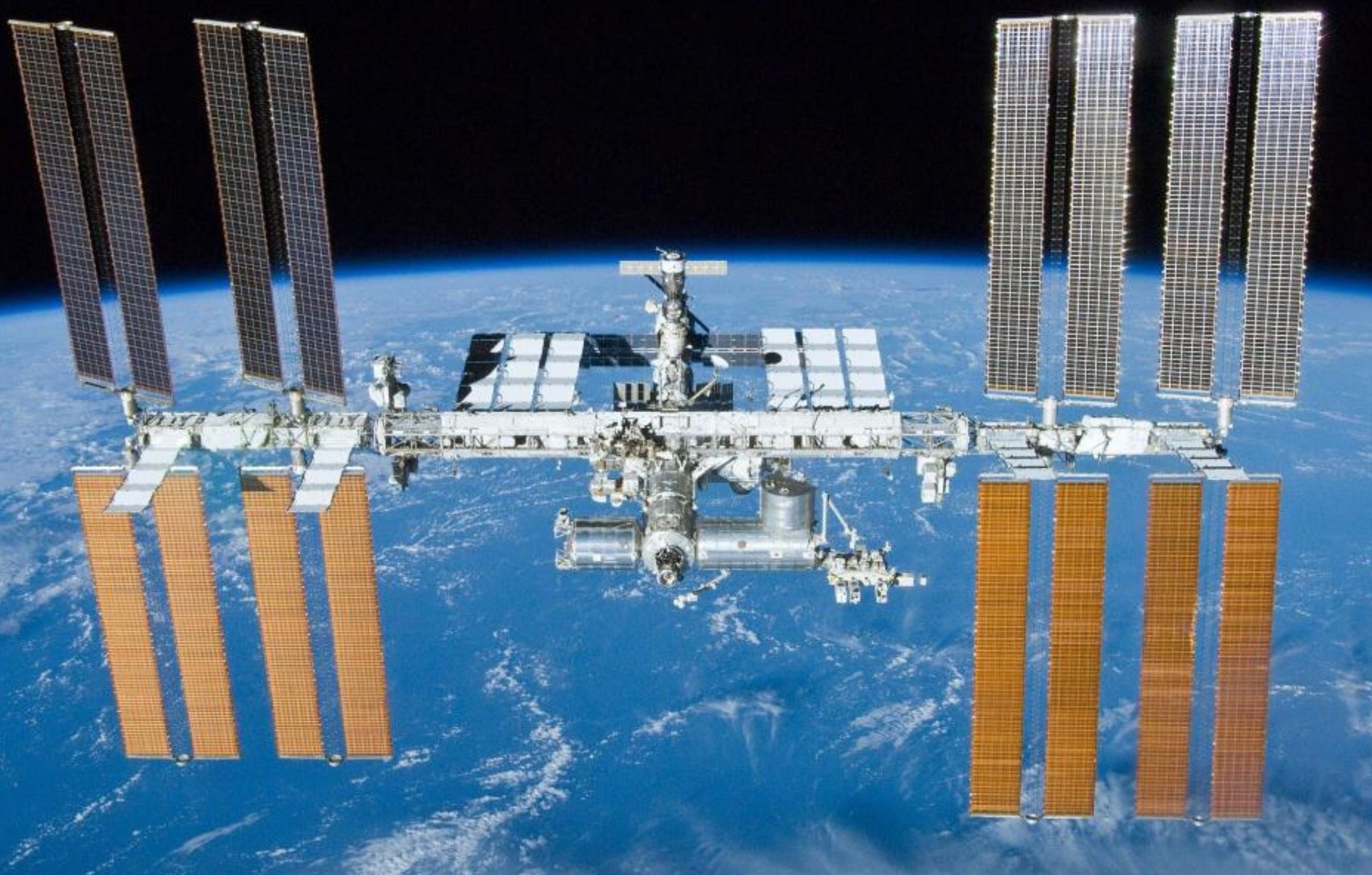




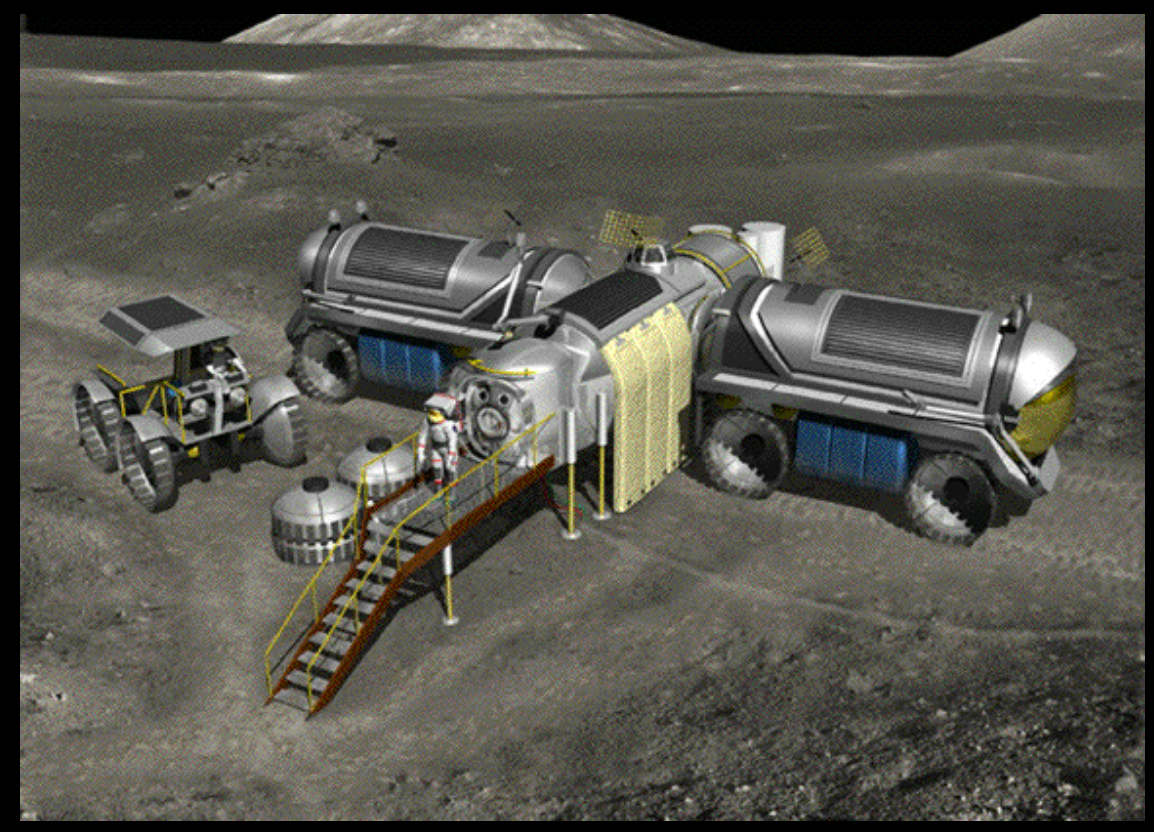




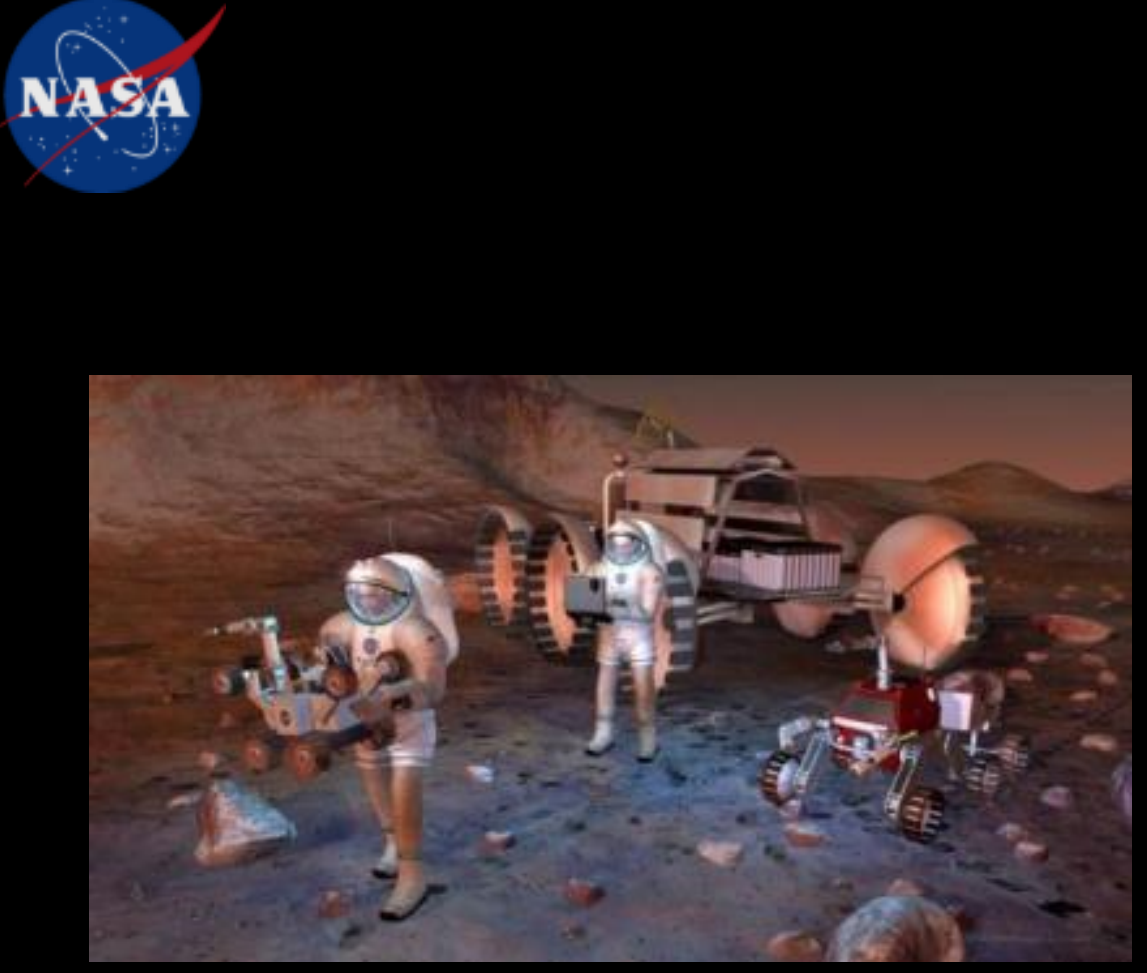

Mars

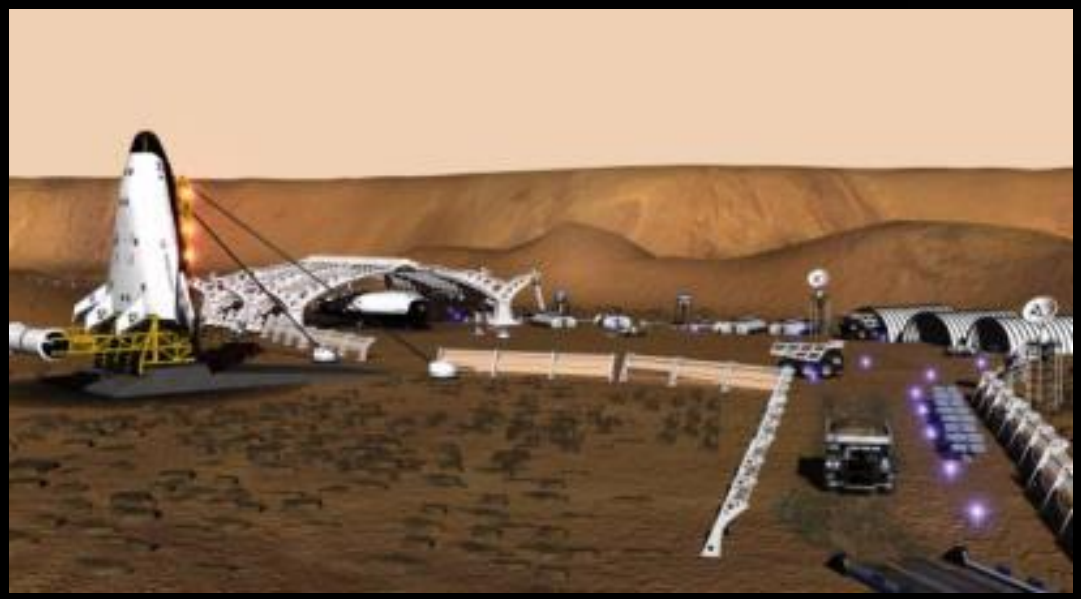


NASA

\section{Atmosphere Management}



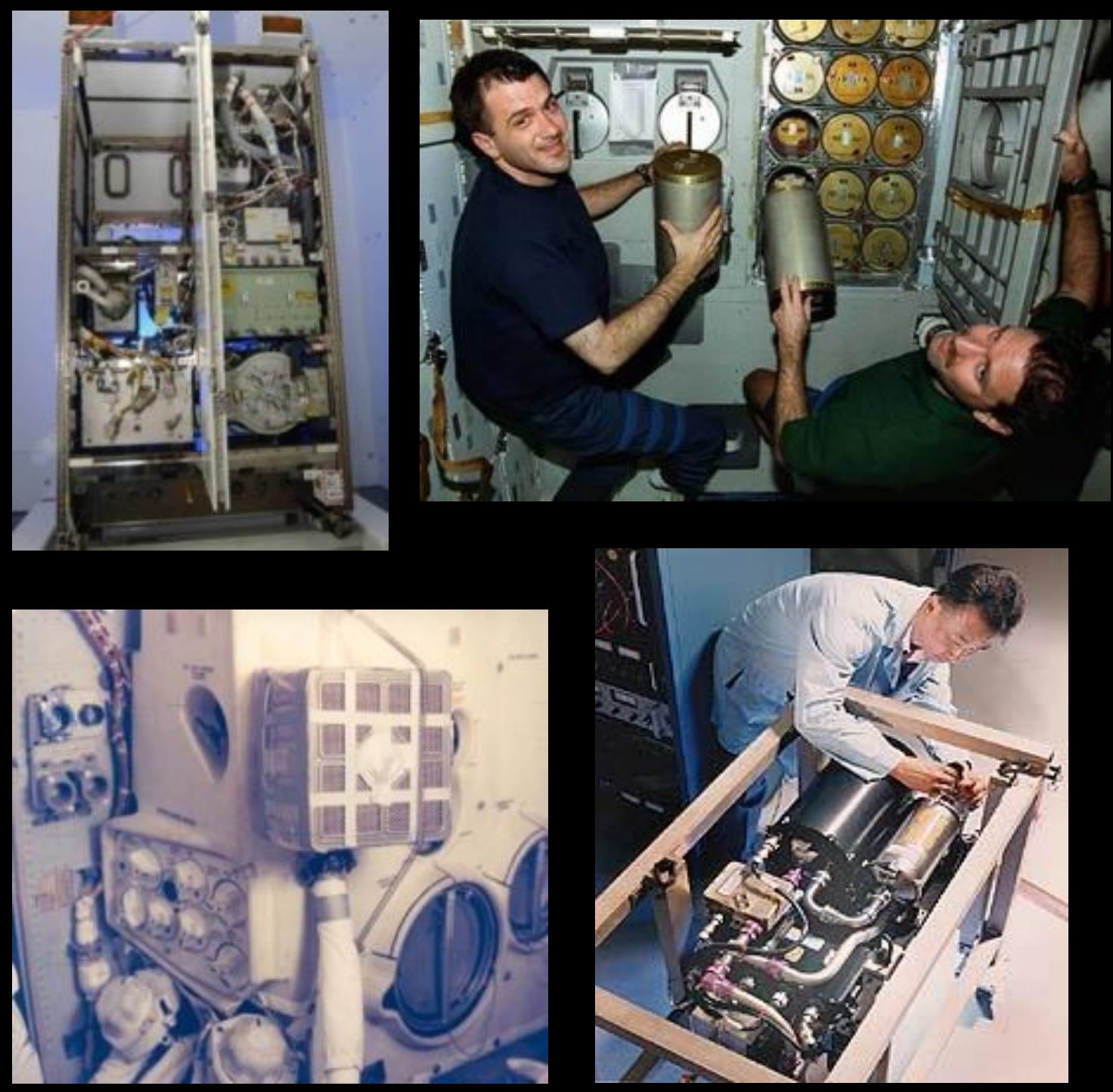

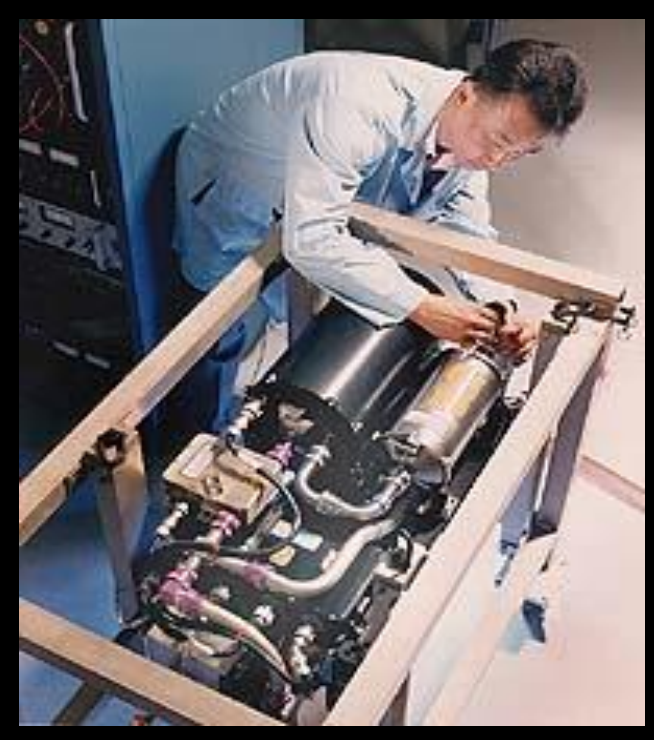

- $\mathrm{O}_{2}$ Generation

- $\mathrm{CO}_{2}$ Removal

- Contaminant Control

- Particulate Control 
Nags $\mathrm{CO}_{2}$ Capture and Sequestration
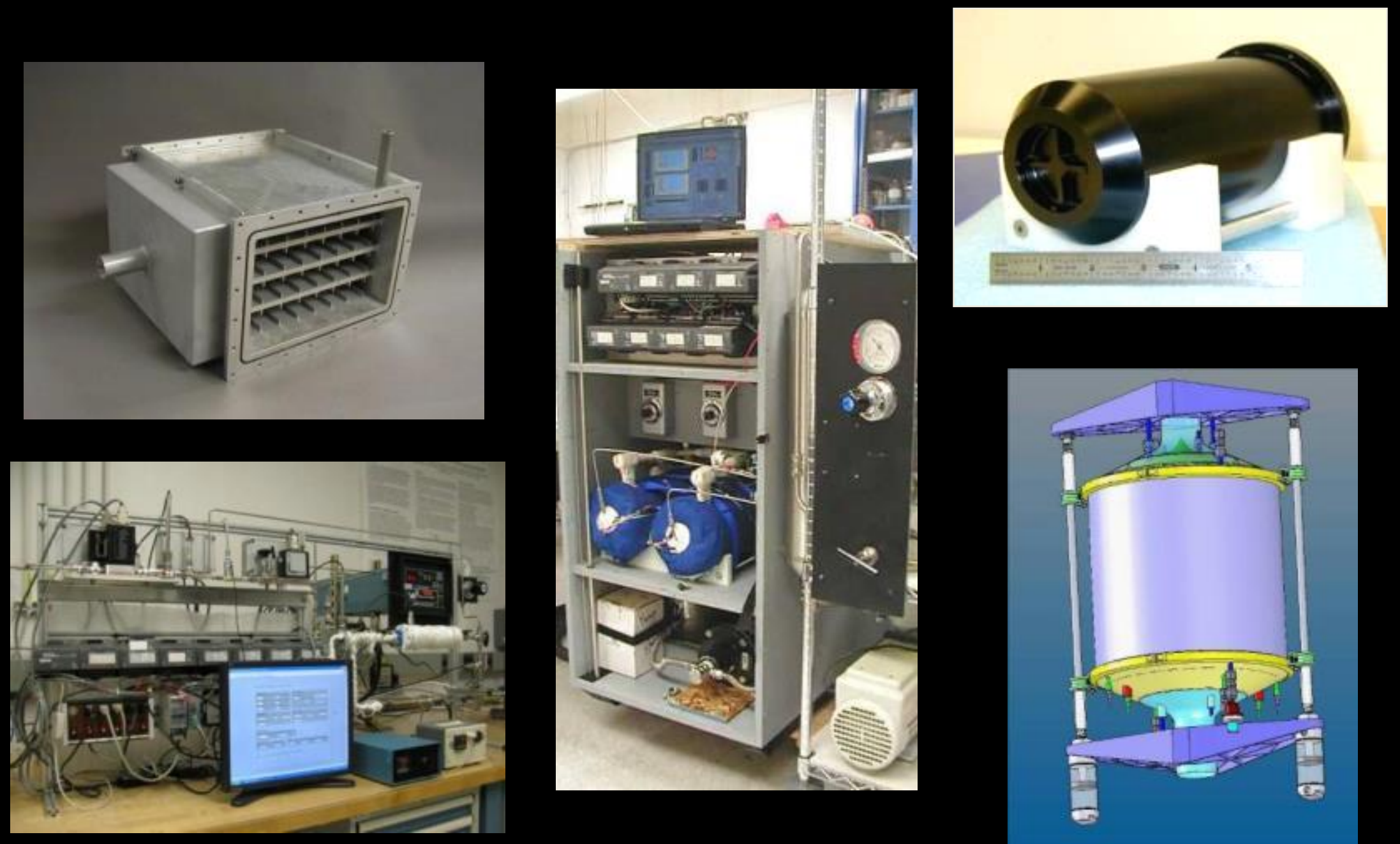


\section{NASA $\mathrm{CO}_{2}$-Based Manufacturing Approaches}

\section{Current Terrestrial Biorefinery Model}

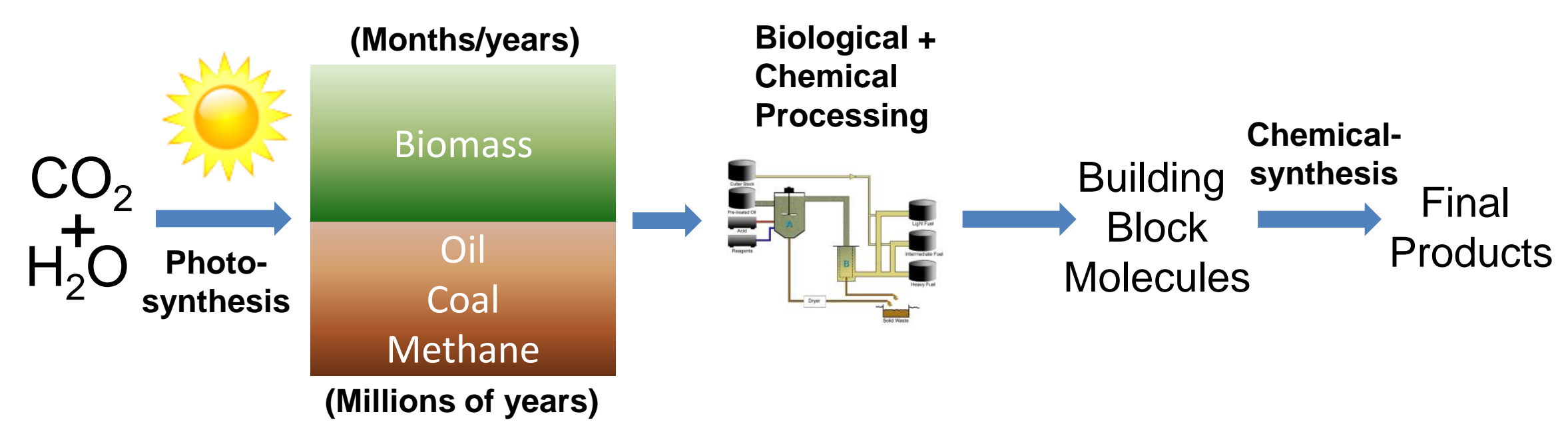

\section{Space Bio-Manufacturing Model}

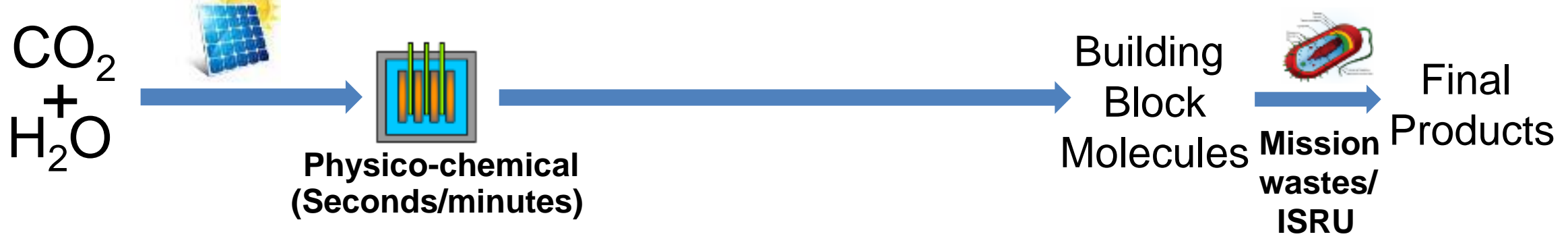




\section{Nasa Wastewater to Drinking Water}

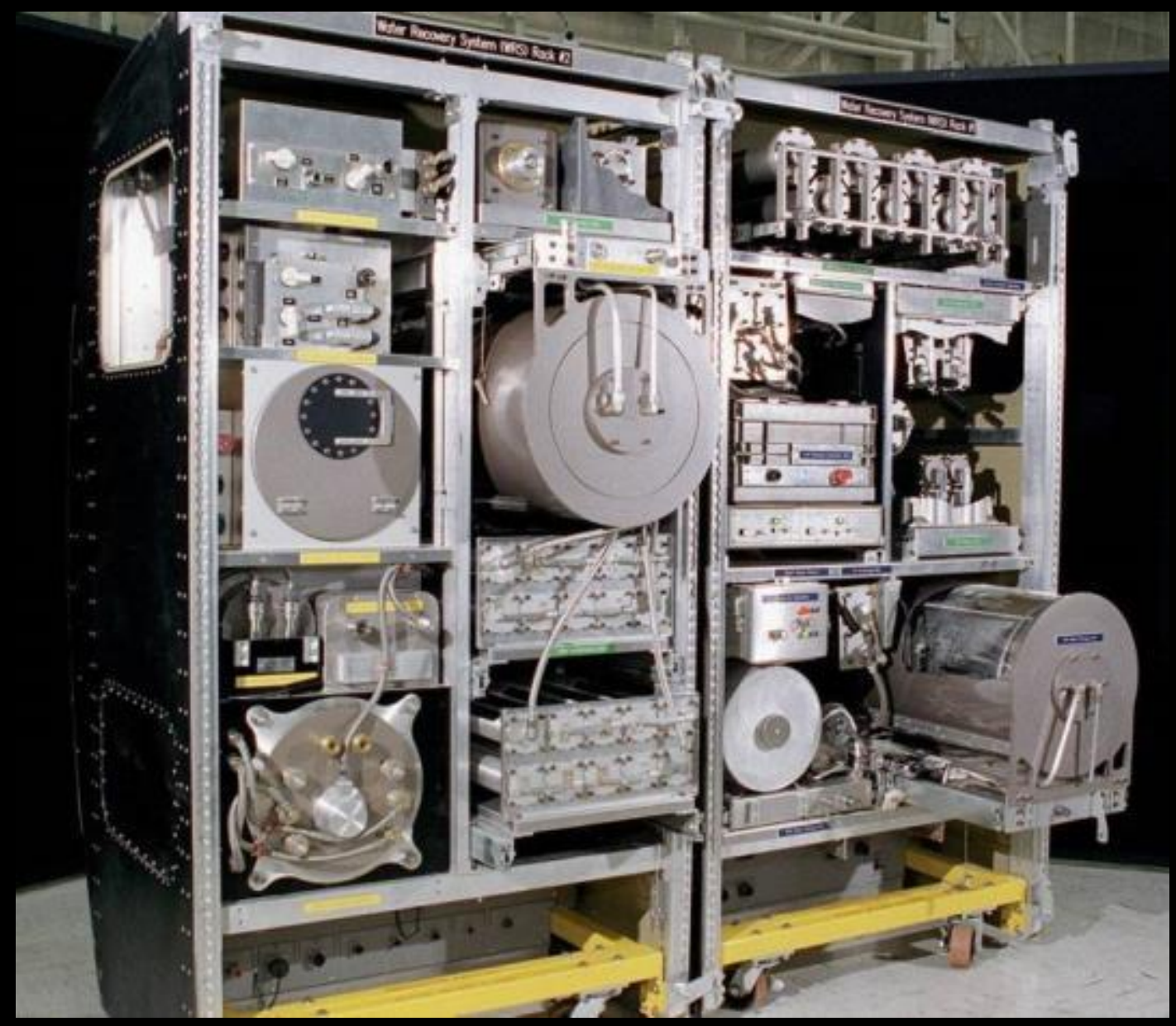

- Disinfection

- Organic Removal

- Inorganic Removal

- Maximize Recovery

ISS Water Recovery Subsystem 


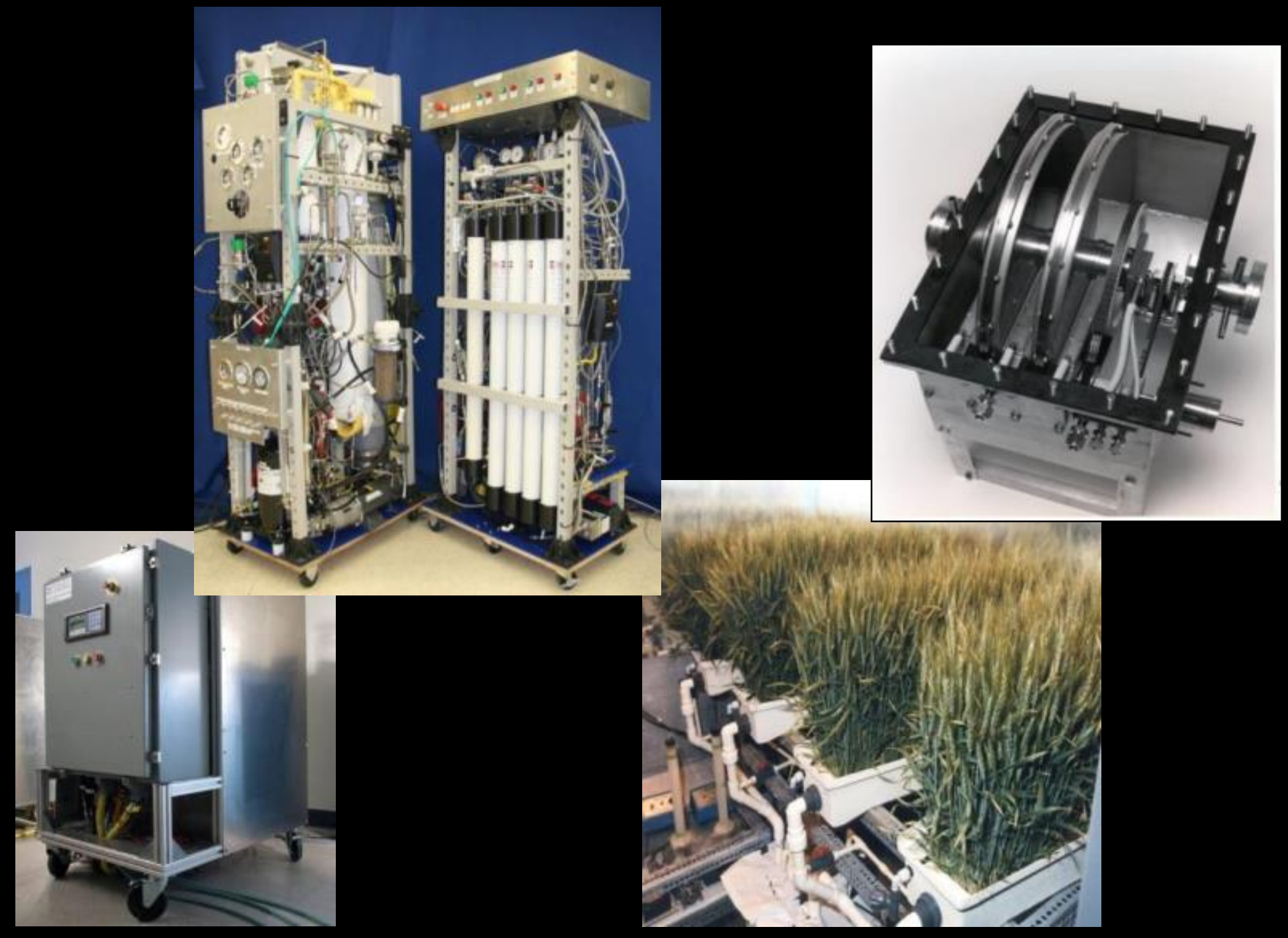




\section{Waste Management}

NASA

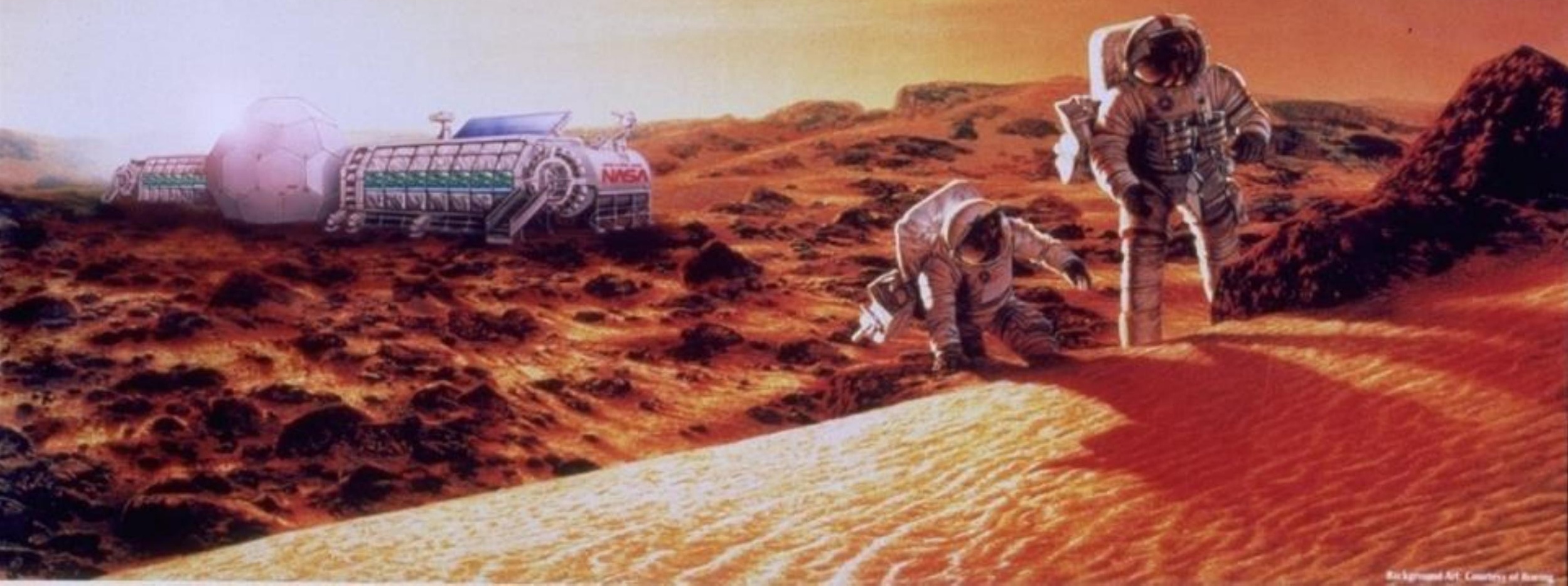


NASA "Waste" Conversion and Reuse ("Cradle to Cradle" Approaches)

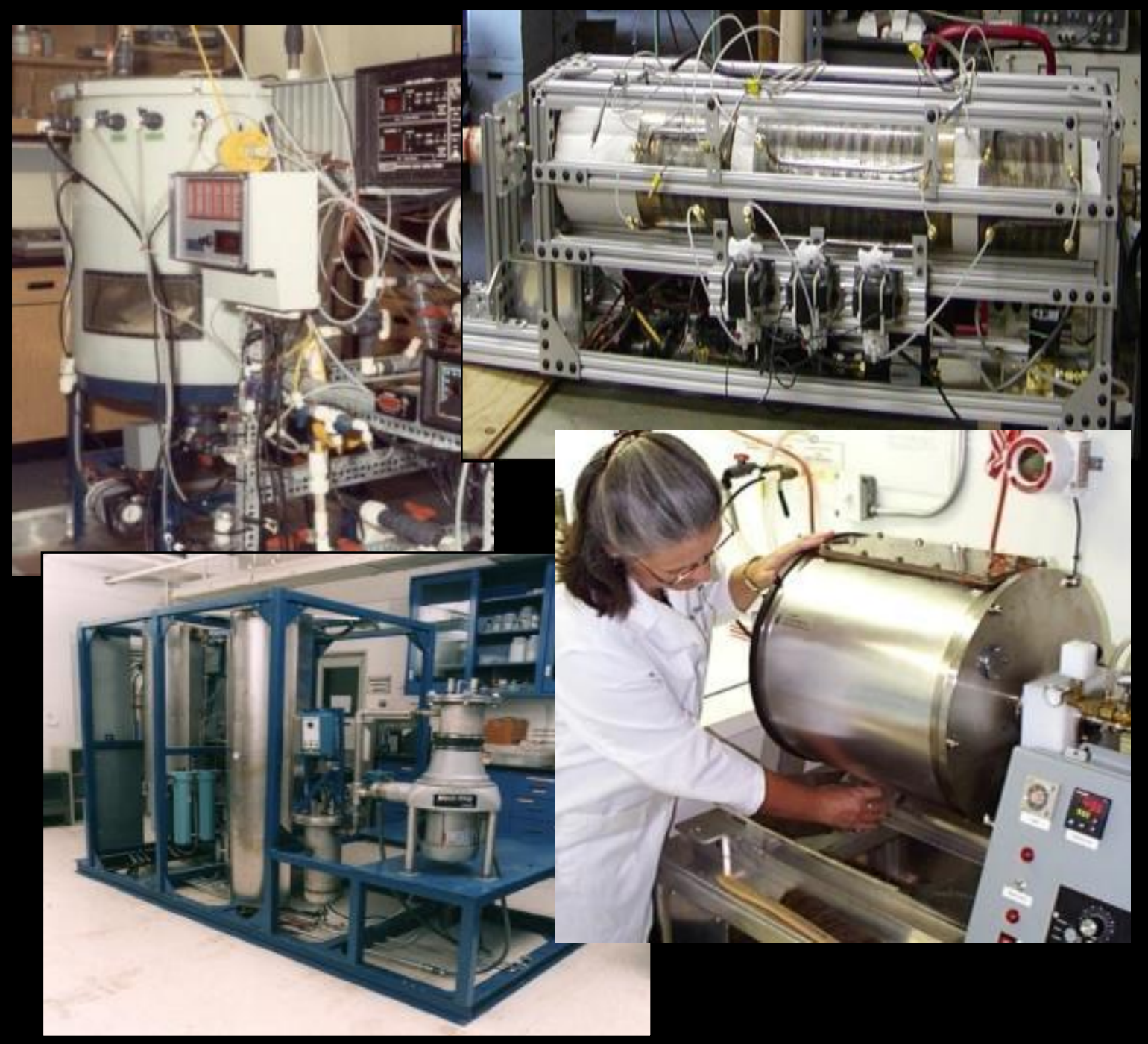

- Volume Reduction

- Odor Control

- Sanitize

- Generate $\mathrm{H}_{2} \mathrm{O}, \mathrm{O}_{2}$, $\mathrm{CO}_{2}$, Fuel, Nutrients, Building Materials 


\section{NASA In Situ Manufacturing}

Utilize unusable mission materials and In situ resources to generate products needed for sustainable systems.

Concept Example:

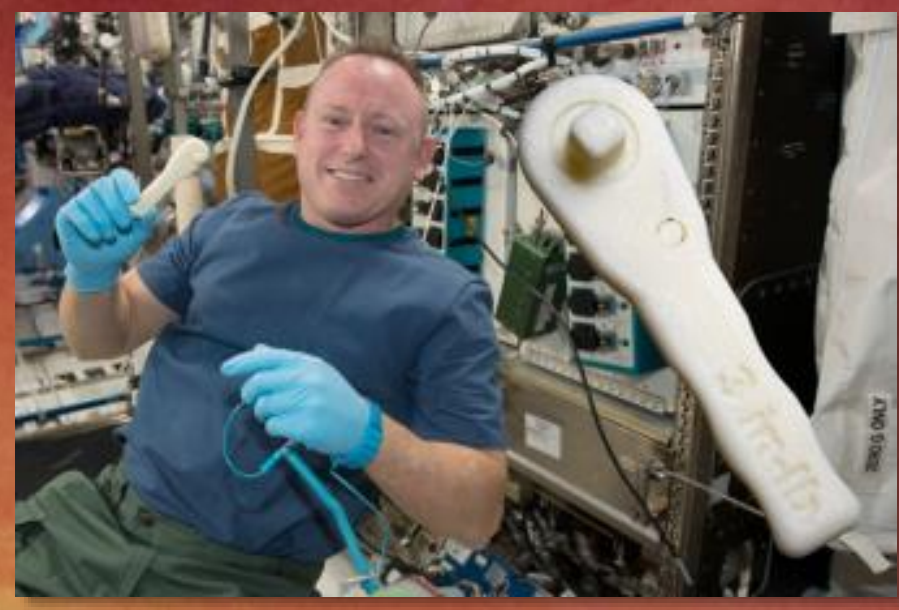

$\mathrm{CO}_{2}+\mathrm{H}_{2}$

P/C Conversion System
Microbial Medium
Products 


\section{Food Production}

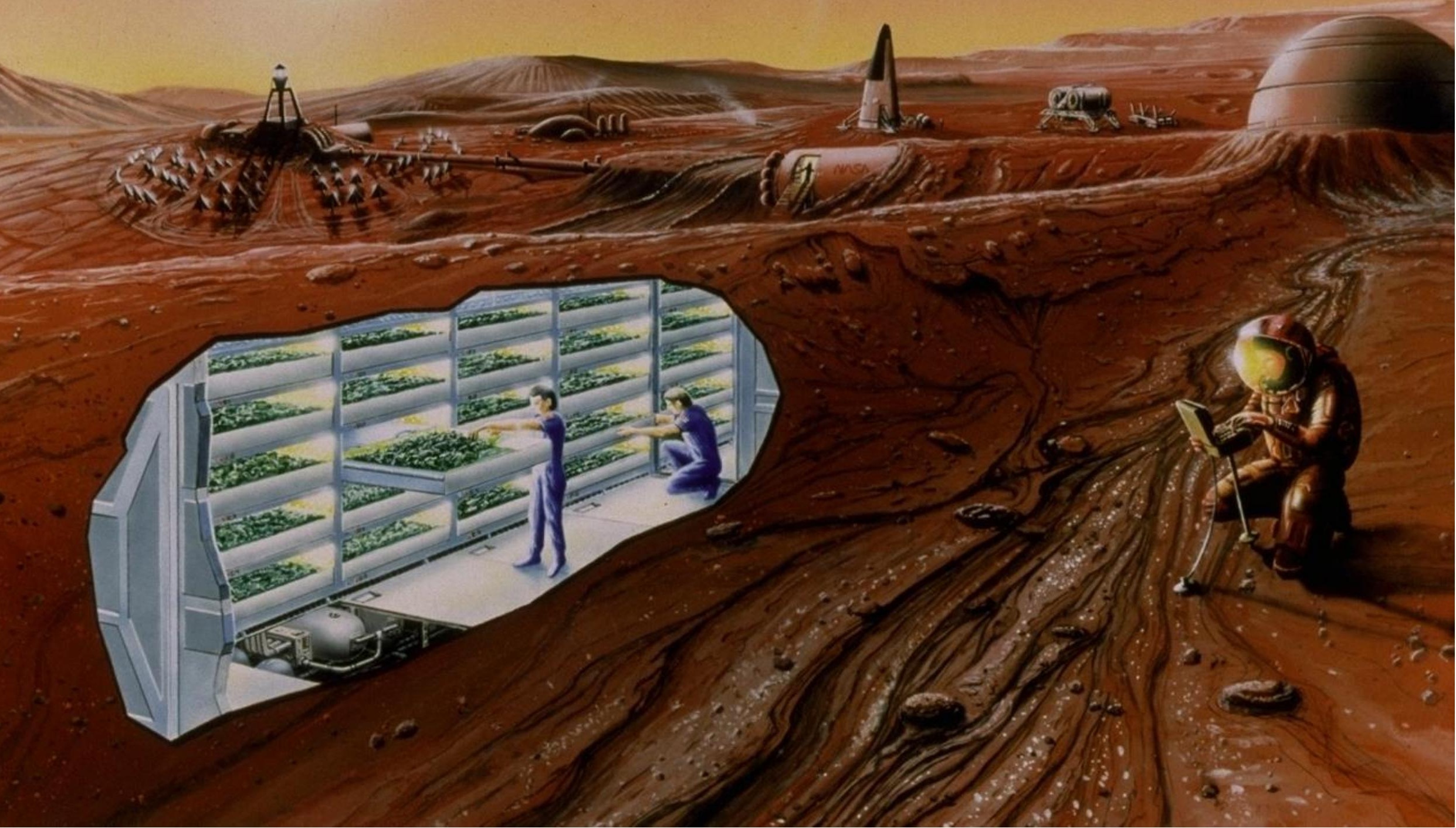




\section{NASA \\ Closed System Agriculture}

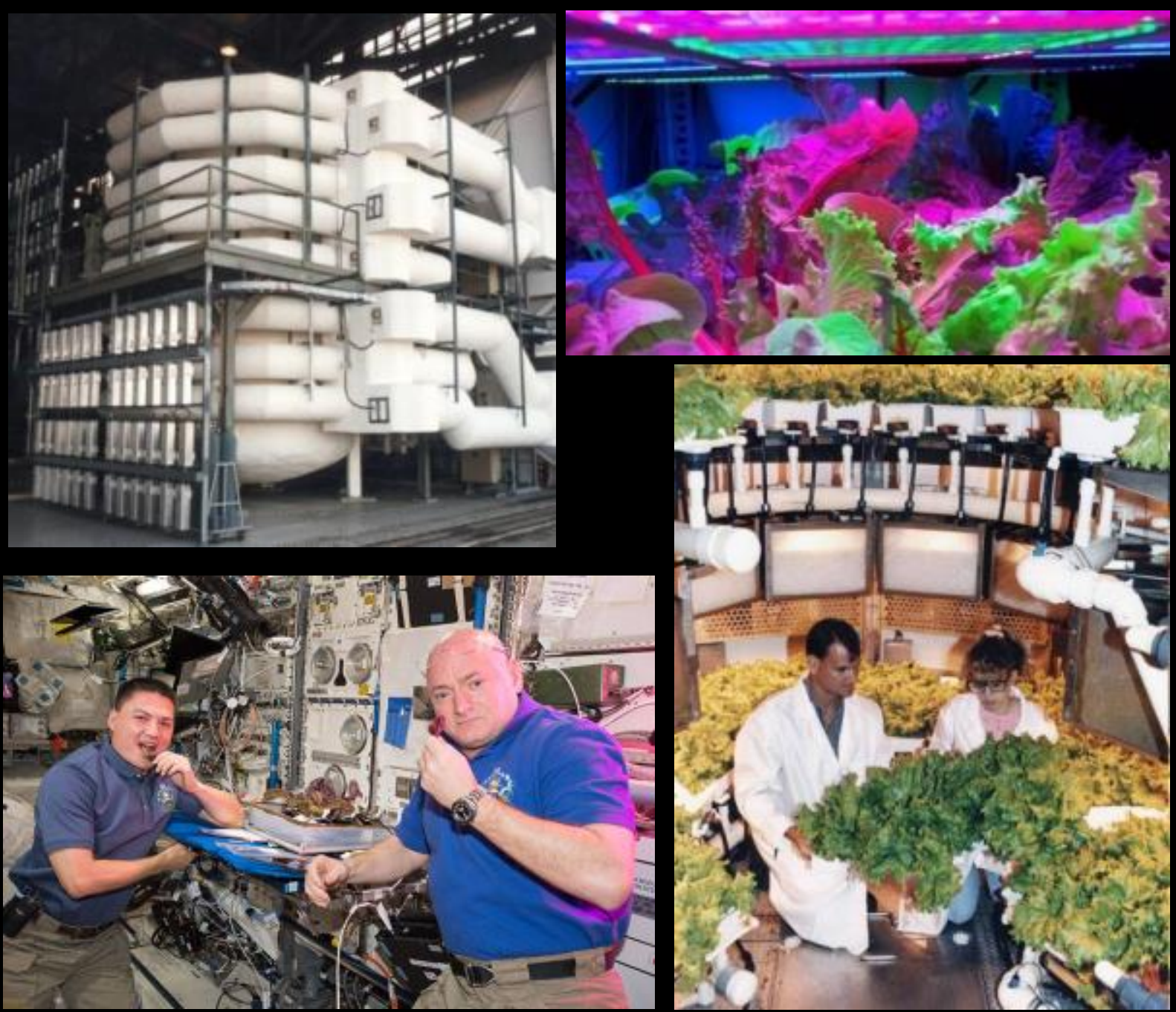

- Maximize Yield

- Low Water

- Efficient Lighting

- Use recovered nutrients 


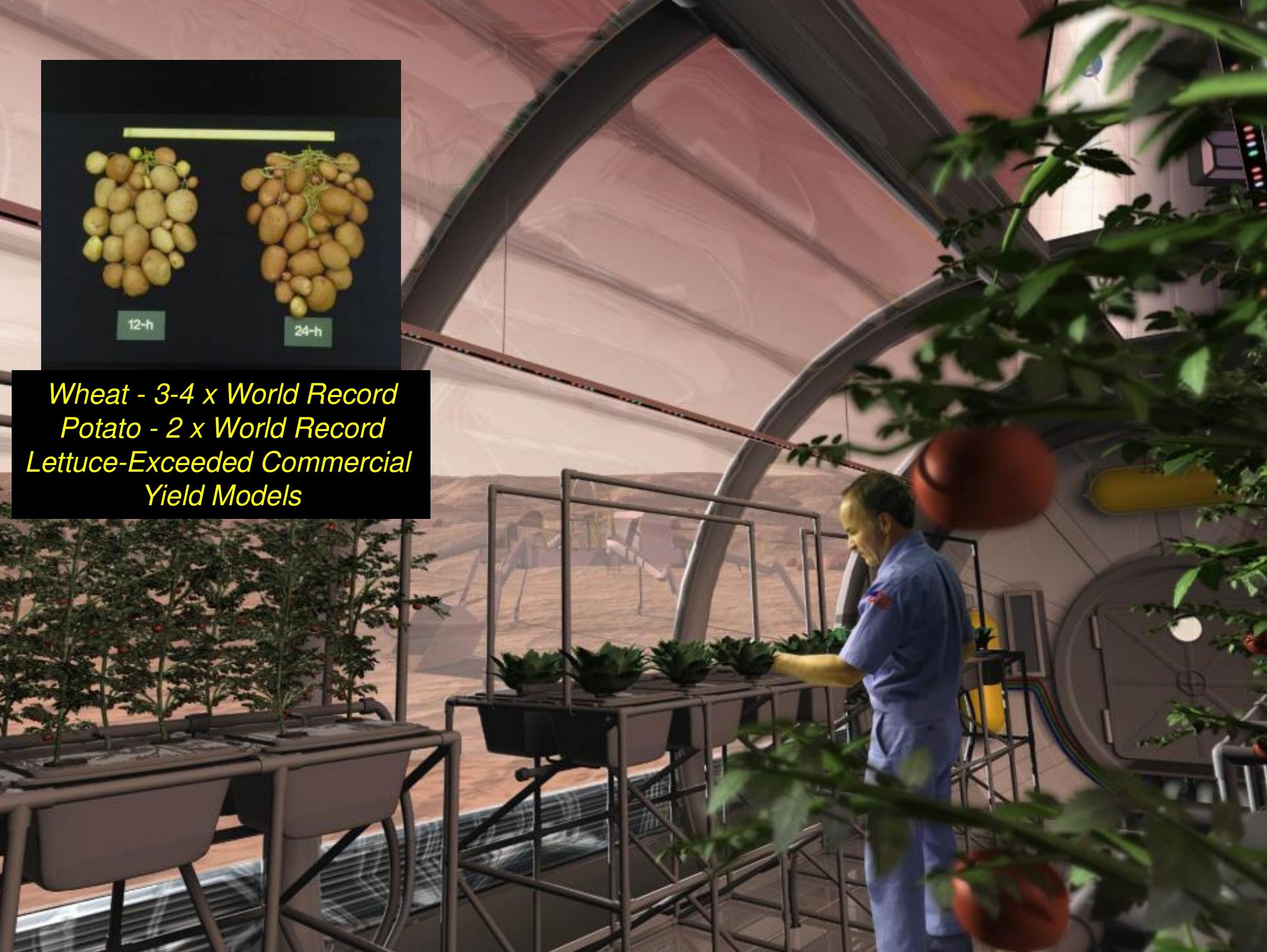




\section{Systems Engineering}

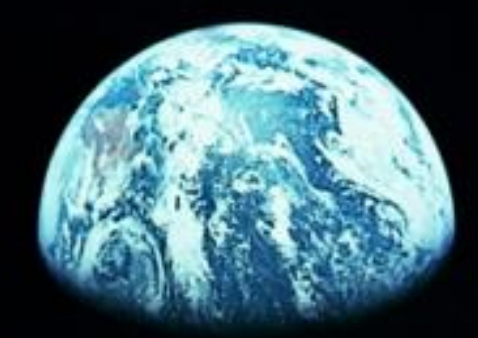




\section{Systems Engineering}

ELSS-RQ35484-C

Earth Systems Program

Earth Life Support Systems Requirements Document

ESD - 34794

Earth Systems Directorate

Requirements Division

August 2006
NASA/SP-2007-6105

Rev1

NASA

Systems Engineering Handbook

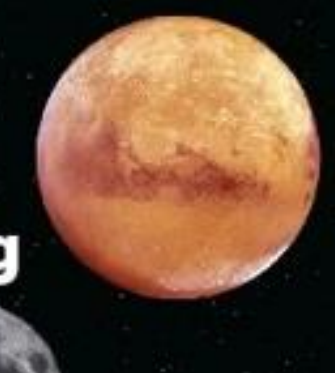




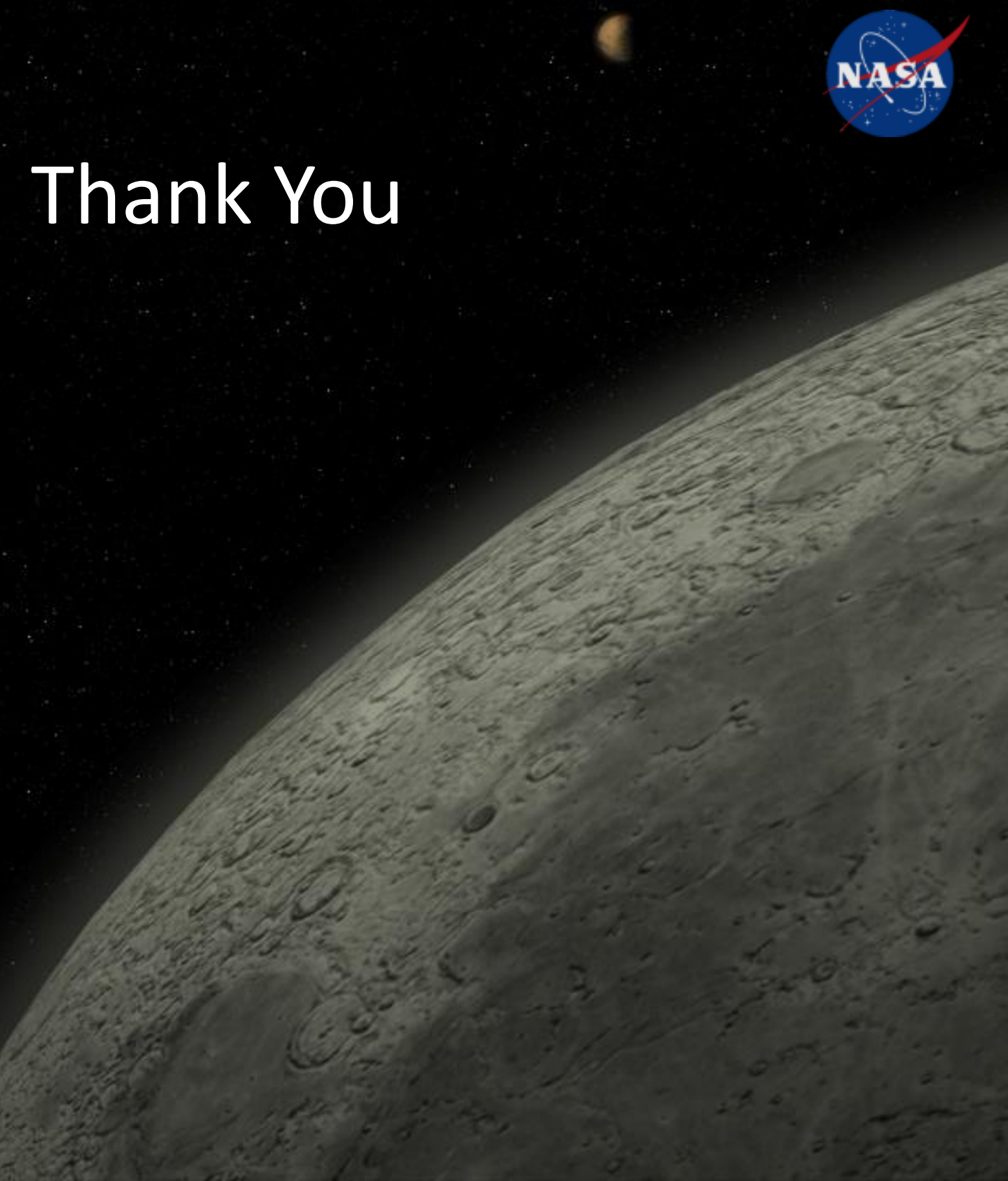

